\title{
"Ideal Speech" on Wikipedia: Balancing Social Marginalization Risks and Social Inclusion Benefits for Individuals and Groups
}

\author{
Amber G. Young \\ University of Arkansas \\ ayoung@walton.uark.edu
}

\author{
Ariel D. Wigdor \\ University of Massachusetts Amherst \\ awigdor@isenberg.umass.edu
}

\begin{abstract}
On Wikipedia, editors use talk pages to debate whether/how to include associations with marginalized social groups in highly visible digital information. Despite efforts to promote social inclusion, digitally cocreated information on Wikipedia is vulnerable to marginalizing content. We study the case of Tim Cook's Wikipedia biography prior to him coming out as a member of the LGBTQ community. Editors cocreating his biography discussed at length whether/how to include information about Cook's sexual orientation. Our critical hermeneutic investigation of these discussions reveals a paradox of social inclusion. That is, efforts by activist editors to promote social inclusion at the group level may bring about the unintended consequence of marginalizing an individual. Applying critical social theories, we conclude that deference should be given to individuals over groups when collaborative decisions are made about whether to publish associations in highly visible digital information. This research highlights the complexity of governance for social inclusion online.
\end{abstract}

\section{Introduction}

Social inclusion is "the ability to participate fully in one's social world" [1]. In contrast, social marginalization is the process through which social groups are restricted from social, economic, and/or political life [2]. Boundaries of marginalized groups may be based on social identifiers such as race, religion, disability, or sexual orientation to name a few. Individuals associated with marginalized groups may experience challenges in the workplace. For instance, mentioning affiliation with a lesbian, gay, bisexual, and transgender (LGBT) organization on a resume reduces applicants' chances of being called for an interview [3]. In the United States, dominant social beliefs about what careers are appropriate for LGBT individuals shape career paths in direct and indirect ways [4]. Harassment of LGBT individuals and subsequent psychological distress may have ramifications in the workplace including suboptimal career development [5]. Given the potential negative consequences of revealing a marginalized social identifier, individuals may adapt to the reality of discrimination by concealing associations with marginalized groups [3]. Associations easily perceived by visual cues (e.g., racial identifiers) may be concealed using technologies with low social presence. Associations not easily perceived through visual cues, such as religion or sexual orientation, may be concealed through nondisclosure. However, the ubiquity of personal information online has made identity segmentation strategies (e.g., disclosing an association with a marginalized group in social but not work contexts) more challenging.

Increasingly, database entries about individuals (e.g., biographies and profiles) are being cocreated online without input from the focal individual. This information may contain marginalizing social identifiers that the individual sought to conceal from the public or an employer. The practice of concealing LGBT or queer/questioning (LGBTQ) sexual orientation is referred to as staying "in the closet". The decision about whether to disclose information about sexual orientation is challenging for many professionals [6] and may be particularly complex for executives who must predict and consider public response worldwide. Anti-LGBTQ views fuel obstacles, even dangers, for LGBTQ individuals seeking to reside in, travel to or conduct business in some regions. Same-sex relations are illegal in 71 countries and punishable by death in six [7]. The experience of coming out of the closet may be extremely difficult even in more progressive countries [8]. Optimally, coming out experiences are the result of an individual acting of their own volition in safe environments [9]. When individuals are outed rather than coming out, negative consequences can be severe, including suicide [10].

Innovative information systems are changing the way individuals receive and process information about the social world. These changes present opportunities for greater social inclusion. For example, ICTs give 
voice to Indigenous groups once silenced by traditional media [11]. However, ICTs may have a paradoxical effect, simultaneously promoting social inclusion and marginalization $[12,13,14,15]$. Thus, theories of how to balance inclusive and marginalizing effects of IS through ethical governance are needed. A community of IS researchers strives to understand how technology can be designed, implemented, and governed to promote social inclusion and reduce social marginalization [2, $16,17,18]$.

In an entirely emancipatory (i.e., freeing or liberating) world, there would be no marginalization because individuals would engage in emancipatory dialogue through communicative action to achieve rationality and consensus around true and moral conclusions [19]. One way to promote emancipation is to design technology-enabled ideal speech situations, wherein consensus is reached through dialogue which involves no coercion or force, "except the force of the better argument" $[19$, p. 25, 20]. Prior research explains that systems like Wikipedia talk pages approximate ideal speech situations and foster emancipation, raising the question: "for whom are such systems emancipatory" and why? [21, p. 53]

In practice, efforts to increase social inclusion in online communities abound [e.g., 22, 23]. In particular, open collaboration communities such as Wikipedia, which structure open participation in collaborative endeavors, exemplify both the promises and challenges of social inclusion [24]. On Wikipedia the lean nature of talk pages underlying highly visible digital information reduces the degree to which symbol sets can be used to persuade or garner undue influence as editors debate which social identifiers should be included in biographies about individuals. Platform restrictions on customization and standardized templates structure information in ways that should minimize information disparities across subjects. Bots actively monitor information and enforce community standards. Activists organize projects to promote objectivity and reduce hate speech and marginalizing content, i.e., content that associates individuals with identifiers of social groups that are restricted from social, economic, and/or political life. Yet, despite efforts to promote social inclusion, digitally cocreated information on Wikipedia is vulnerable to marginalizing content [24]. This raises the question: for whom is co-created digital information promoting social inclusion and how can governance promote inclusive outcomes for marginalized individuals and groups?

\section{Literature Review}

\subsection{Social Inclusion and Emancipation}

Emancipation is a complex construct, often studied in component parts $[13,25]$. Emancipatory functions of IS relate to several components of emancipation including, "truth exposure, democratization, community enhancement, inclusion, creative expression, economic facilities, political liberties, and facilitation of social change" [11, p. 343]. Recently, IS scholars released a rallying cry for research focusing on the social inclusion component of emancipation [1].

The field of IS has recently devoted much attention to issues of social inclusion of a variety of marginalized groups. For instance, IS researchers have examined how systems can be used to promote social inclusion of refugees $[16,26,27]$ and people with disabilities [14, $28,29,30]$. A prominent theme in the IS social inclusion literature relates to gender diversity in the IT workforce $[31,32,33]$. Researchers interested in IT use at different stages of life have studied social inclusion of children [34], college students [35] and the elderly [36, 37, 38].

There is a large body of work which addresses the social inclusion of people in locations lacking development in areas such as economic opportunity, education, and technological infrastructure [39]. This research is often geared toward educating the public and shaping policies for greater inclusion. A major finding of this stream of research is that those who could benefit most are often unable to leverage the emancipatory potential of IS due to the digital divide. For instance, oppressed groups who could benefit most from digital activism are least likely to have the technology or understanding to carry out successful protests online [12]. When patients turn to crowdfunding to avoid medical bankruptcy, those experiencing the greatest financial duress are least likely to raise substantial funds [40]. While the Web holds promise as a tool to bridge the income gap between rich and poor, a digital divide in both web site traffic and access to technology inhibits economic efforts of those in low-income countries [41]. Digital inequalities which lead to marginalization intersect with a variety of socio-economic factors [17] including education level [35]. Even when efforts are made to bridge the digital divide, individuals may be marginalized in social systems built and reified through IS [18].

\subsection{Digital World Impacts on Social Inclusion and Marginalization in the Physical World}

Increasingly, personal information about individuals is being generated online for public 
consumption. When information contains marginalizing social identifiers, individuals are at risk for negative consequences in the physical world. For instance, women in Iran who post hijabless photos anonymously on social media risk physical violence if identified in the physical world [42]. Due to the impact of digital information in the physical world, digital activism has become an important means of pursuing social and political change. Effects of digital information activism go beyond online communities to affect action repertoires in the physical world [43, 44, 45]. Notably, digital activism brings the possibility of unintended negative consequences for individuals and new forms of domination and harassment $[2,46,47]$. A review of the literature on digital activism finds that there are six main impacts of digital activism on individuals in the physical world (i.e., cognitive, emotional, financial, operational, reputational, and power [48]). Together, the reviewed studies reveal how digital information and digital activism impact individuals' experiences of social inclusion and marginalization in the physical world.

\subsection{Balance Theory and Marginalizing Social Identifiers}

As society increasingly relies on the Internet for information, concern grows that much digital content is inaccurate or incomplete and that digital content may be easily altered, plagiarized, written misleadingly, and/or posted anonymously under false pretenses. Even when information is accurate, privacy and the potential for information use as a tool for marginalization are concerns. Individuals or groups relegated to the margins of society tend to find themselves out of reach of the kinds of social acceptance, power and prosperity enjoyed by those in the center of society. Emancipation, in contrast, involves "the enactment of new, less oppressive worlds" [11, p. 343] wherein individuals can be the "authors of their own lives" [49, p. 290].

The effects of marginalizing digital information can be far-reaching. Notably, marginalizing information can shape cognitions toward not only the individual of interest, but also any topics that a reader associates with the focal individual. Balance theory suggests that when an individual comes to associate something liked with something disliked, the individual will experience cognitive dissonance until cognitive balance is restored [50]. Cognitive balance is achieved when the individual reconciles the attitude differential by coming to like or dislike both things. In this manuscript, we apply balance theory to explain the dynamics and far reaching consequences of social inclusion and marginalization through digital information.

When marketers use commercials to associate a product (like a computer) with something or someone about whom a customer has a positive attitude (like a celebrity), the marketers create a positive association between the celebrity and the product. If the customer has a positive association with the celebrity, the customer may cognitively balance to associate positively with the product. Conversely, if the customer has a negative association with the celebrity, the customer may cognitively balance to negatively associate with the product. The effects of cognitive balance can be far-reaching and irrational. For example, marginalizing attitudes toward a minority group, when extended to a minority CEO, have been found to balance with negative attitudes toward all corporations run by minority CEOs [51].

When individuals cocreate digital information about an individual online, they must consider which associations to include. For instance, memberships in religious organizations, socio-cultural background information, or labels such as LBGTQ may be included in digital information about individuals. When an individual's association with a marginalized group is revealed through highly visible digital information, the association may bring unwanted attention to the individual. This attention may put the individual at risk to those who would target the individual to enforce marginalizing power dynamics.

\subsection{Critical Social Theories and Identity in a Digital World}

Critical social theories provide a lens for viewing the world in ways which challenge "social conditions and institutions and oppressive forms of control, often enabled and supported by IS, which prevent realization of humane, just and free organizations and society" [52, p. 442]. Questions around what constitutes or facilitates marginalization and emancipation are a dominant theme in critical social theories. Critical social theories are uniquely suited for application to the study of the digital cocreation of information as this process entails moral judgments by editors about what content is "valid" and "good". Critical theorist Jürgen Habermas [53] suggests that ideal communication is a key to preventing social ailments such as injustice, ideological domination, and marginalization. Ideal speech requires an ideal speech situation - "a situation in which everyone would have an equal chance to argue and question, without those who are more powerful, confident, or prestigious having an unequal say" [54, p. 178]. Such situations require shared language, sincerity, democratization of input, a normative or enforced social order, lack of coercion, and truthfulness [55]. Hansen and colleagues [21] explain that Wikipedia's talk pages are designed to approximate an ideal speech situation and should, theoretically, foster emancipatory outcomes. 
Ideal speech situations are theorized to support consensus as intersubjective meanings are agreed upon and rationality allows the valid position to prevail. Still, the validity of the "true" position may not be universally accepted as norms differ across cultures [53]. Though theoretically intriguing, ideal speech situations alone do not always result in idealistic or utopian outcomes [56]. Rather, ethical discourse in ideal speech situations may be used in conjunction with economic bargaining to promote rationality and order [56, 57]. Absent economic constraints, negotiations rely on the integration of ethical concerns into the decision-making discourse. In such cases, the importance of the speech situation increases, and ideal speech situations should facilitate convergence around emancipatory outcomes.

In determining which position is emancipatory, a deliberating group should consider moral values, which are the basis for affording respect and dignity to individuals. Beyond the individual, morality is associated with principles of community solidarity [58], protecting "the web of intersubjective relations of mutual recognition by which these individuals survive as members of a community" [53, p. 200]. Individuals and associated social groups have a synergistic relationship - the social group gives an individual a sense of self, an identity - and can take that sense of self away [59]. Likewise, social groups cannot function without individuals actively giving a sense of self to others in the group. This mutual dependency between the individual and the individual's social group puts both in a precarious position when interests conflict (i.e., what is best for the individual is not best for the social group, or vice versa). Where interests do not align, the individual may concede to promote group solidarity. Alternatively, the group may concede, working to "save face" for the individual and preserve the individual's identity [59]. Normatively, in cases of mutual consideration, deference should be given to the individual because individuals are vulnerable and have fragile identities [53].

\section{Method}

We take a critical and interpretive approach to investigate how marginalization can be an unintended consequence of contributors' anti-marginalization efforts. Having identified a unique case in which contributors actively justify contributions as "right" or inclusive, we follow the rationale of Yin [60] and pursue a single-case design around the debate over whether to include information about Apple CEO Tim Cook's sexual orientation in Cook's Wikipedia biography prior to Cook publicly coming out as gay. This debate takes place on Wikipedia talk pages. Deemed suitable for critical interpretive studies [61], the hermeneutic theory of understanding underlies our approach to case study. At one time, critical theories and hermeneutic methods were seen as incompatible. But since the 1990s, IS researchers have integrated critical and interpretive theories and methods [62]. Once underrepresented in IS research [63], recent critical research has provided crucial insights into IS phenomena such as ICT4D [18], digital activism [12], and the development of liberated spaces in online communities [64]. Critical hermeneutics has specifically been used to study digital content such as websites [11] and email [65].

According to Myers and Klein [66, p. 17], critical research applied to the IS literature "is concerned with social issues such as freedom, power, social control, and values with respect to the development, use, and impact of information technology." Critical research can contribute to "emancipatory social change by going beyond the apparent to reveal hidden agendas, concealed inequalities and tacit manipulation" [67, p. 142]. Though rigid application of methodologies constrains creativity, it can be beneficial to evaluate critical research using general criteria [52, 68]. Alvesson and Deetz [69] describe three aims of critical research: insight, critique, and transformative redefinition.

\subsection{Anti-Marginalization Activism and the Case of Tim Cook's Wikipedia Profile}

The case studied in this research involves the outing of Tim Cook as gay on Wikipedia. Cook became CEO of Apple Inc. in 2011 after having served as interim CEO during Steve Jobs' medical leave. For years, Cook chose to remain in the closet. His decision to conceal his LBGTQ association is not uncommon among executives. It has been argued that "expecting Tim Cook to be openly gay would be to completely forget gay history" [70]. For instance, John Browne resigned as CEO of BP in 2007 after being outed as gay with "no illusions he'd ever be chairman or chief executive of another publicly traded company" [71, para. 3]. Browne, whose mother suffered under the Nazis during World War II, describes being "acutely aware that gays were also victims of the Holocaust" [71, para. 15]. Like Browne, Cook grew up "deeply conscious of discrimination around him" having witnessed acts of terror such as cross burning [70, para. 4].

After years of public speculation on digital media including Wikipedia, Cook was outed on television by journalist Simon Hobbs in 2014 [72]. Soon after, Cook published an essay confirming that he is gay [73]. On The David Rubenstein Show, Cook explained that the reason he remained silent about his sexual orientation for years is that he was "trying to do something that is comfortable to me, which is to stay private" [74, para. 7]. Cook says that being out, while helpful to others who 
likewise have been "ostracized" based on social identifiers, has come at a personal price [74]. Describing his experience of being gay, Cook explains that it gives him insight into what it is like to be a minority and has required him to develop a thick skin [73].

Prior to Cook publicly coming out as gay, Wikipedia contributors were challenged by the dilemma of whether to include information about Cook's sexual orientation in his profile. The talk pages underlying the biographical profile of Tim Cook stand out due to the richness and perceived sincerity of the justifications around whether/how to include Cook's sexual orientation in the information being digitally cocreated. Though activists on either side of the debate disagree about what is right, both sides exhibit a concern for what is emancipatory. Data predating Cook's [73] essay was collected from his Wikipedia profile by retrieving all underlying talk page data (i.e., 24 discussion threads on two talk pages $[75,76])$. Of these 24 , five discussion threads with 47 comments address Cook's sexual orientation and link to a related thread with 166 comments, which we collected from Wikipedia's biographies of living persons noticeboard (BLPN) [77].

\section{Justification for Inclusion and Exclusion}

First, we present editors' justifications for inclusion. Some activists assert that including information about Cook's sexual orientation, although speculative, would empower the LGBT community. That is, revealing the positive association between Cook and the LGBTQ community may prompt readers with a positive view of Cook to achieve cognitive balance by associating positively with the LGBTQ community. Given Cook's status as a prominent business leader of one of the world's largest technology companies, activists argue that, if confirmed, claims about his sexual orientation would cement Cook's position as "the most powerful homosexual man in the world" (anonymous). It is argued that Cook coming out as gay would have profound implications for the LGBT community and provide an avenue for Cook to serve as a role model and symbol of progressive social reform. Some activists argue for inclusion of Cook's sexual orientation, drawing from Wikipedia's notability policy: "his sexuality is notable" (anonymous). Others assert that a failure to include Cook's sexual orientation reduces information quality: "The gaping hole being that he has been hailed in reliable sources as the most powerful gay person in tech, the most powerful gay person in the world, and the most influential LGBT individual" (Irn). One anonymous activist states:

"What an extravagant farce. Both this discussion and the extended one in the archive are attempts to legitimate homophobia. Speculation about Tim
Cook's sexual orientation is widespread, and notable, journalistic magazines like Out have already referred to his homosexuality. Gay teens lose another potential role model because straight tech geeks / Baby Boomers are threatened by a gay man running one of the world's most powerful companies. The exclusion of any sexual orientation information from the article - or even barring readers from awareness of the long-standing discussion of Tim Cook's homosexuality in other, less timid media - is shameful. Is Wikipedia a source of information, or a rubber stamp for rightwing sensibilities?" (anonymous)

The justification that omitting sexual orientation distorts information has been discussed at length in the field of education, where researchers theorize that a history of omitting information about historical figures' sexual orientation skews understanding of LGBT prevalence throughout history [78]. As inclusion represents an empowering stance for the LGBT community, exclusion may suppress the already marginalized group. Arguably, by omitting speculative claims that would otherwise elevate the group, a "glass closet" may be formed. That is, a social norm that LGBT people in high-profile positions hide their sexual orientation may be established. This case is made by activists who suggest that leaving out Cook's sexual orientation will stifle the LGBT community's quest for social inclusion in the physical world. This perspective aligns with concerns that dominant social systems systematically omit information about sexual orientation from legitimated information sources to enforce the status quo. Deciding which details to include or exclude in biographic information sends signals about what information is relevant, notable, and important. As Irn points out, "to ignore it is to pretend that it never happened or that it's not important."

Next, we present editors' justifications for exclusion. Though some activists in favor of including information about Tim Cook's sexual orientation cite concerns about homophobic motives for suppression, activists arguing to exclude this information cite alternative reasons for their position. Some activists address accusations of homophobia head on. AV3000 writes, "Please WP:AGF. The editors involved in earlier discussions have attempted to interpret WP policies (WP:BLP in particular) to the best of their abilities." WP:AGF refers to the Wikipedia policy advising editors to assume good faith and approach all disagreements with the presumption that everyone involved has good intentions. WP:BLP refers to Wikipedia policies guiding the generation of information for biographies of living persons. Another activist pushes back against accusations of homophobia: "As long as we live in a homophobic world, I'm not 
willing to be the editor who adds that paragraph." (Mark Asread). This comment references the real and consequential nature of anti-LGBT sentiment in the lifeworld beyond Wikipedia. When some activists suggest that speculation about Cook's sexual orientation be included as a controversy rather than having Cook listed as gay, some activists resist. Ken Arromdee writes that it is "likely to be an undue weight problem to mention it at all." Notably, a subject's straight orientation is rarely mentioned. Another activist suggests that including speculation about Cook's orientation could have harmful consequences: "Absolutely, 100\% NO...Doing so would set a very dangerous precedent” (Griswaldo).

Activists in favor of exclusion, like activists in favor of inclusion, credit themselves with having good intentions. They cite a responsibility to protect the individual from violations of his personal privacy. LadyofShalott writes, "we have no business repeating the speculation of others on what is essentially a personal and private matter." Alison states, "Tim Cook is, as the Reuters blog points out, 'intensely private', so I think it would be highly inappropriate to propagate these unfounded rumors in his BLP."

Just as some activists in favor of including information about Cook's sexual orientation accuse opposing activists of homophobia, some activists in favor of excluding information about Cook's sexual orientation accuse opposing activists of dubious motives. Off2riorob writes, "Although Cook has never discussed or commented on his sexuality the Homosexual community demanded he 'come out' of what they referred to as his 'glass closet' and be a role model for other LGBT people."

One activist asserts that the LGBT community has attempted to force Cook to "come out" by way of the LGBT blogging community propagating the speculation about Cook's sexual orientation. This concern is a running theme in the overall conversation:

"Wikipedia is not a blog, it is not a trashy tabloid, and most importantly, it isn't an appropriate arena for sections of the [LGBT] communities to pursue a campaign to 'out' people on the basis of rumour. Given the harm that has been done to [LGBT] individuals in the past as a result of such rumourmongering, one might hope for a little more restraint." (AndyTheGrump)

In addition to physical threats, individuals may incur a social tax for their association with the LGBT community. If information about an individual's career is presented without mention of the individual's membership in a marginalized community, the focus is on the career (e.g., "Cook is an acclaimed CEO"). Mention of the individual's membership in a marginalized community, however, may distract focus from the intended message (e.g., "Cook is an acclaimed, gay CEO"). Use of the adjective "gay" qualifies Cook's LGBT affiliation to his status as an acclaimed CEO. As such, it prompts the reader to evaluate and cognitively balance Cook's CEO status alongside his association with the LGBT community. Additionally, undue effort directed at figuring out whether/how to present information about an individual's sexual orientation may detract from efforts to improve other areas of that individual's profile. An anonymous editor writes:

"I realize this article is being intentionally limited to a discussion of Tim Cook's sexuality, and as such has no room for anything regarding his business activities. Which, unfortunately for you, is what most readers would be interested in. Yet another black eye for Wikipedia." (anonymous)

Battling back and forth, activists on either side of the debate add and remove information about Cook's sexual orientation, posting justifications in the talk pages. Activists are unable to reach a consensus until Cook publicly comes out as gay on October 30, 2014 [73], after which his LGBT association is included.

\section{Discussion}

Information systems researchers have expressed optimism that digital technologies are renewing the public sphere by empowering those once marginalized by traditional media [11]. Digital technologies have been credited with reducing media corruption [79], promoting social inclusion [16], and improving wellbeing [80]. At the same time, IS researchers have warned that empowerment is not enjoyed by all [12] and there are "dark side" effects of digital technologies and digital activism [81, 82]. As digitization revolutionizes the interactions and social processes shaping society, IS researchers are tasked with understanding the complex and sometimes paradoxical effects of technology.

Notably, we observe in this case that efforts toward emancipatory design and governance did not foster consensus. Contributors were unable to agree on what was emancipatory. Pitted in their dichotomous views, activists with opposing perspectives overrode and reverted content changes in a perpetual editing war. Vandalism and malevolence have been imputed as causes of poor information quality in digitally cocreated information [83], as has unconscious bias [84]. This research augments current understanding by revealing that even when online collaboration community contributors have good intentions, recognize the impact of marginalization, and work toward social inclusion, emancipatory outcomes can prove elusive. Our findings suggest that the digital information co-creation process on Wikipedia involves democratization of decisions about who experiences social inclusion (in this case, the 
group or the individual). Given the fragility and vulnerability of individuals, Habermas [53, 85] theorizes that, normatively, deference should be given to an individual over a group because individuals are more vulnerable than groups and individual identities are fragile. Paradoxically, by working to reduce marginalization against the LGBT community, activist editors provided facilitating conditions for marginalization of an individual. This research reveals how associations involve intertwined effects for marginalized individuals and marginalized groups that should not be overlooked. While individuals may choose to associate themselves with a marginalized group, such associations should be voluntary.

\section{Implications for Theory and Practice}

Information systems that afford control of digital information are tools of power that can enable social inclusion or marginalization of individuals and groups on an unprecedented scale. At one time information systems were believed to be neutral and value free, but recent innovations make plain that information systems and IS research are innately political [86, 87]. As such, ethical and emancipatory design theories are needed for preserving individual human agency and dignity in the digital age. The power of information systems lies not only in design but also in implementation, governance, and patterns of use. Prior research describes the challenges of democratic debate and control online, concluding that if information systems are neutral, "no new checks and balances are needed" but if information systems afford social ills new checks and balances are needed [88, p. 222]. There is another possibility; information systems can foster social good. This research highlights that just as new checks and balances are needed if systems are tools for marginalization, new checks and balances are needed if systems are to be tools for social inclusion-as is the goal of Wikipedia's founders. Information systems researchers are poised to develop these checks and balances by building on critical social theories to inform not only systems design, but every aspect of socio-technical systems. Development of emancipatory governance policies contributes value in multiple streams of IS research.

As IS researchers strive to understand how systems can be designed, developed, implemented, and governed in emancipatory ways, it is important first to understand the obstacles to social inclusion. Our study reveals that a socially inclusive outcome did not materialize because users' motivations to do good were directed orthogonally at targets with interrelated, yet conflicting interests. This research suggests that emancipatory outcomes remain elusive due to the nature of power and privilege. Drawing again from balance theory, we apply the analogy of a seesaw-for balance to be achieved, both ends cannot rise. Extending this metaphor to Cook, he had to lose the privilege that came with being assumed straight to empower the LGBTQ community. Critical social theories can guide the discussion as value judgements are made about how to channel the power of IS ethically.

Successful critical research meets three criteria related to insight, critique, and transformative redefinition [69]. By providing insight into who is emancipated by dominant digital information cocreation processes and how, we answer call for research on uneven effects of emancipatory efforts in open collaboration [21]. We also address the call for research into how information is affected by collaborative platforms and processes [89]. Though big data studies abound, we address a gap in understanding that stems from insufficient qualitative and critical research on digital information and ethical cocreation of information. We hope this research will serve as an invitation to others to embrace critical social theories to develop more comprehensive guidelines and policies for emancipatory, socially inclusive IS. The effects of such guidelines and policies in different design contexts should be tested through empirical research.

By critiquing the practice of prioritizing the wellbeing of a group over the well-being of an individual when making decisions about how to use an information system, we shed light on how social inclusion can be acted out in the digital information co-creation process. Recently, IS researchers have emphasized the importance of developing specific, implementable policy recommendations based on theory [90]. Thus, we propose that an emancipatory policy be added on open collaboration communities and other digital information and news sources that defer such decisions to individuals over groups:

In cases where individuals are speculated to be associated with a marginalized community (e.g., with regard to sexual orientation, religion, ethnicity, disability, or health, etc.) association with the community should be excluded unless a minimum of two reputable sources demonstrate that the individual has publicly confirmed (without ambiguity) and brought attention to their association with that community.

This policy can protect individuals from risks associated with highly visible, digital, marginalizing information. We also propose also a more radical technology policy regarding human agency in digital representations:

Individuals should be allowed to choose which associations are listed in their public profiles.

Giving this agency to individuals will empower individuals to author their own lives. Emerging 
technologies such as digital identities [91] will make this process feasible and verifiable.

Our transformative redefinition of antimarginalization activism as marginalizing provides a novel way of thinking about digital activism. In this age of protest, it can be difficult to measure societal outcomes of digital activism [48]. Micro-effects, on the other hand, are easier to measure. Dorothy Leidner describes an incident in Texas where a medical professional's poor word choice sparked a digital activism campaign that cost him his career without necessarily leading to any positive change for the marginalized group the campaign supposed to promote [2]. When individuals are targeted or become collateral damage of digital activism campaigns, the vast reach of the Internet can make it difficult to escape the social media spotlight. Targeting individuals as part of a social campaign may (or may not) be a way to bring social justice, but such efforts come at an individual cost. This cost may be paid by high-profile individuals who are notable enough to have a Wikipedia page or be covered by mass media outlets. However, increasingly, information about everyday citizens such as middle managers, professors and realtors is being cocreated online and diffused worldwide. Thus, marginalization and agency discussions related to IS are becoming more salient to common people also.

\section{Limitations and Future Research}

In different settings and periods other social identifiers become politically charged. For instance, during World War II Jewish women went to great lengths not to "look Jewish" including bleaching or shaving hair and wearing dark glasses to conceal eye color [92] Today, patients may avoid getting tested or seeking treatment for COVID-19 due to the stigma associated with catching the disease [93]. Though this research considers only one social identifier, the findings and proposed policies have implications which extend beyond the LGBTQ community. The policies recommended by this research are not, however, intended to generalize beyond information about living persons. Future research should consider what policies to apply to digital cocreation of information about individuals who are deceased. A unique aspect of our approach is that sincere others might use the same method to formulate different policies. Such alternate perspectives would contribute to the awakening of critical consciousness in IS researchers and multifaceted understandings of digital cocreation of emancipatory information. Implications of competing ethical frameworks applied to individual privacy in this context would be a valuable avenue for future research.
Our interpretations are informed by our backgrounds as IS researchers. Thus, we have written this paper from an IS perspective drawing on IS literature. There is a vast literature on public discourse and counterpublics from which we could have drawn to situate our findings in a broader, less techno-centric debate about human dignity and identity representation. In fact, IS scholars have called for interdisciplinary research into social marginalization in digital contexts [94]. Future interdisciplinary research would enrich understandings of social inclusion and emancipation.

We are aware that this research may be viewed as cultural imperialism, wherein authors not part of the focal marginalized group study issues of marginalization. Additional interpretations should be explored by researchers of diverse backgrounds for more robust understanding. Our case involves association with the LGBTQ community, which may not be perceived as marginalized in some cultures or in the future. Yet, if history is any indication, social identifiers of some sort will continue to be used to systemically marginalize social groups. This research will remain relevant, but the social identifiers of interest will change over time. Future research should consider how differences in types of social identifiers might affect the applicability of the policies developed herein or necessitate the development of additional policies. We call for the academic community to support practitioners and guide future research by contributing theoretical knowledge toward the development of a comprehensive set of design theories and emancipatory policies for digital cocreation of information. We further call for more research into the emancipatory and oppressive potentials of information systems.

\section{References}

[1] A. Bailey et al., "JAIS special issue CFP: Technology and social inclusion", AIS (Feb. 2020).

[2] J. Ortiz et al., "Giving voice to the voiceless: The use of digital technologies by marginalized groups", Communications of the AIS, vol. 45, 20-38, 2019.

[3] A. Tilcsik, "Pride and prejudice: Employment discrimination against openly gay men in the United States", American J. of Sociology, 117, 2, 586-626, 2011.

[4] C.J. House, "Integrating barriers to Caucasian lesbians' career development, and Super's life-span, life-space approach", Career Dev. Quarterly, 52, 3, 246-255, 2004.

[5] C. McFadden, "Lesbian, gay, bisexual, and transgender careers and human resource development: A systematic literature review", H. R. Dev. Rev., 14, 2, 125-162, 2015

[6] R. Feintzeig, "Why gay workers decide to stay in the closet", Wall Street Journal (May 2014).

[7] BBC News, "India gay sex ruling: Where in the world is gay sex still against the law?", $B B C$ (Sep 2018). 
[8] M.A. Lourie, "Unlocking the closet door: Recurrent identity disclosure experiences among LGBTQ students", Academic Medicine, 93, no. 4, 522-523, 2018.

[9] C. Albert, and S. Bettez, "Opening the closet door: Exploring the role of social media in the coming out process for individuals who self-identify as lesbian, gay, bisexual, and/or queer (LGBQ)", AMCIS, 2012.

[10] K. Hendricks, P. Tsibolane, P., and J.-P. van Belle, "Cyber-harassment victimization among South African LGBTQIA+ youth", IFIP Proceedings, Springer, 2020.

[11] A.G. Young, "Using ICT for social good: Cultural identity restoration through emancipatory pedagogy", Information Systems Journal, 28, no. 2, 340-358, 2018.

[12] J.J. George, and D.E. Leidner, "Why marginalized groups struggle to leverage digital activism", AMCIS, 2018.

[13] S.M. Miranda, A. Young, and E. Yetgin, "Are social media emancipatory or hegemonic? Societal effects of mass media digitization in the case of the SOPA discourse", MIS Quarterly, vol. 40, no. 2, 303-329, 2016.

[14] F. Pethig, and J. Kroenung, "Specialized information systems for the digitally disadvantaged", Journal of the AIS, vol. 20, no. 10, 1412-1446, 2019.

[15] J. Rault, "White noise, white affects: Filtering the sameness of queer suffering", Feminist Media Studies, vol. 17 , no. 4, 585-599, 2017.

[16] A. Díaz Andrade, and B. Doolin, "Information and communication technology and the social inclusion of refugees", MIS Quarterly, vol. 40, no. 2, 405-416, 2016.

[17] J.J.P. Hsieh, A. Rai, and M. Keil, "Understanding digital inequality: Comparing continued use behavioral models of the socio-economically advantaged and disadvantaged", MIS Quarterly, 32, no. 1, 97-126, 2008.

[18] C.I.C. Lin, F. Kuo, and M.D. Myers, "Extending ICT4D studies: The value of critical research", MIS Quarterly, vol. 39, no. 3, 697-712, 2015.

[19] J. Habermas, "Reason and the rationalization of society", The Theory of Communicative Action, Beacon, 1984.

[20] D. Cecez-Kecmanovic, and M. Janson, "Communicative action theory: An approach to understanding the application of information systems", ACIS, 1999.

[21] S. Hansen, N. Berente, and K. Lyytinen, "Wikipedia, critical social theory, and the possibility of rational discourse", Information Society, 25, no. 1, 38-59, 2009.

[22] P.M. Baker et al., "Communities of participation: A comparison of disability and aging identified groups on Facebook and LinkedIn", Telematics and Informatics, vol. 10, no. 1, 22-34, 2013.

[23] R. McMillen, and F. Alter, "Social media, social inclusion, and museum disability access", Museums \& Social Issues, vol. 12, no. 2, 115-125, 2017.

[24] A.G. Young, A.D. Wigdor, and G.C. Kane, "It's not what you think: Gender bias in information about Fortune 1000 CEOs on Wikipedia", ICIS, 2016.

[25] P.G. Cerny, "Globalization and the erosion of democracy", Euro. J. Pol. Res., vol. 36, no. 1, 1-26, 1999.

[26] S. AbuJarour et al., "ICT-enabled refugee integration: A research agenda", Communications of the AIS, vol. 44, 874-890, 2019

[27] A. Díaz Andrade, and B. Doolin, "Temporal enactment of resettled refugees' ICT-mediated information practices", Information Systems J., 29, 145-174, 2018.
[28] D. Heath, and R. Babu, "Theorizing managerial perceptions, enabling IT, and the social inclusion of workers with disabilities", Information and Organization, vol. 27, no. 4, 211-225, 2017.

[29] L. Newman et al., "Applying a critical approach to investigate barriers to digital inclusion and online social networking among young people with disabilities", Information Systems Journal, 27, no. 5, 559-588, 2017.

[30] S. Shethia, and A.A. Techatassanasoontorn, "Experiences of people with visual impairments in accessing online information and services: A systematic literature review", Pacific Asia J. of the AIS, 11, no. 2, 39-66, 2019.

[31] H. Annabi, and S. Lebovitz, "Improving the retention of women in the IT workforce: An investigation of gender diversity interventions in the USA", Information Systems Journal, vol. 28, no. 6, 1049-1081, 2018.

[32] J.J. Baroudi, and M. Igbaria, “An examination of gender effects on career success of information systems employees", Journal of MIS, 11, no. 3, 181-201, 1994.

[33] B. Gupta et al., "A field-based view on gender in the information systems discipline: Preliminary evidence and an agenda for change", Journal of the AIS, vol. 20, no. 12, 1870-1900, 2019.

[34] N. Iivari et al., "Exclusions in social inclusion projects: Struggles in involving children in digital technology development", Information Systems Journal, vol. 28, no. 6, 1020-1048, 2018.

[35] J. Sims, R. Vidgen, and P. Powell, "E-learning and the digital divide: Perpetuating cultural and socio-economic elitism in higher education", Communications of the AIS, vol. 22, 429-442, 2008

[36] G. Fox, and R. Connolly, "Mobile health technology adoption across generations: Narrowing the digital divide”, Information Systems J., 28, 6, 995-1019, 2018.

[37] J.C.Y. Lam, and M.K.O. Lee, "Digital inclusivenesslongitudinal study of Internet adoption by older adults", Journal of MIS, vol. 22, no. 4, 177-206, 2014.

[38] S.K. Srivastava, and P.K. Panigrahi, "Social participation among the elderly: Moderated mediation model of information and communication technology (ICT)", Communications of the AIS, vol. 44, 698-717, 2019.

[39] L. Kvasny, and M. Keil, "The challenges of redressing the digital divide: A tale of two US cities", Information Systems Journal, vol. 16, 23-53, 2006.

[40] G. Burtch, and J. Chan, "Investigating the relationship between medical crowdfunding and personal bankruptcy in the United States: Evidence of a digital divide", MIS Quarterly, vol. 43, no. 1, 237-262, 2019.

[41] K. Abernethy, and H. Reichgelt, "Global diffusion of the Internet II: National differences in web site connectivity", Communications of the AIS, vol. 12, 739-751, 2003.

[42] M. Stewart, and U. Schultze, "Producing solidarity in social media activism: The case of My Stealthy Freedom”, Information and Organization, 29, 3, 2019.

[43] A. Kavada, "Connective or collective? The intersection between online crowds and social movements in contemporary activism", The Routledge Companion to Media and Activism (pp. 108-116), Routledge, 2018.

[44] O. Oh, C. Eom, and H.R. Rao, "Role of social media in social change: An analysis of collective sense making 
during the 2011 Egypt revolution", Information Systems Research, vol. 26, no. 1, 210-223, 2015.

[45] L. Selander, and S.L. Jarvenpaa, "Digital action repertoires and transforming a social movement organization", MIS Quarterly, 40, no. 2, 331-352, 2016.

[46] U. Dolata, and J. Schrape, "Masses, crowds, communities, movements: Collective action in the internet age", Social Movement Studies, 15, 1-18, 2016

[47] A. Young, L. Selander, and E. Vaast, "Digital organizing for social impact: Current insights and future research avenues on collective action, social movements, and digital technologies", Information and Organization, vol. 29, no. 3, 100257, 2019.

[48] J.J. George, and D.E. Leidner, "From clicktivism to hacktivism: Understanding digital activism", Information and Organization, vol. 29, no. 3, 100249, 2019.

[49] A. Díaz Andrade, and C. Urquhart, "Unveiling the modernity bias: a critical examination of the politics of ICT4D”, Info. Tech. Dev., vol. 18, no. 4, 281-292, 2012.

[50] F. Heider, The Psychology of Interpersonal Relations, Wiley, New York, 1958.

[51] H.R. Dixon-Fowler, A.E. Ellstrand, and J.L. Johnson, "Strength in numbers or guilt by association? Intragroup effects of female chief executive announcements", Strategic Management Journal, 34, 12, 1488-1501, 2013.

[52] D. Cecez-Kecmanovic, "Doing critical information systems research - Arguments for a critical research methodology", European J. of IS, 20, 4, 440-455, 2011.

[53] J. Habermas, Moral Consciousness and Communicative Action, MIT Press, Cambridge, 1991.

[54] R.A. Wallace, and A. Wolf, Contemporary Sociological Theory, Prentice Hall, Upper Saddle River, 1999.

[55] J. Habermas, Justification and Application: Remarks on Discourse Ethics, MIT Press, Cambridge, 1993.

[56] J. Habermas, "Three normative models of democracy", The Inclusion of the Other, MIT Press, 1998.

[57] J Habermas, Between Facts and Norms, MIT Press, 1996.

[58] P. Gingrich, "Jürgen Habermas" (Feb 2006).

[59] E. Goffman, Stigma: Notes on the Management of Spoiled Identity, Simon \& Schuster, New York, 1963.

[60] R.K. Yin, Case Study Research, SAGE, London, 2003.

[61] T. Butler, "Towards a hermeneutic method for interpretive research in information systems", Journal of Information Technology, vol. 13, no. 4, 285-300, 1998.

[62] M.D. Myers, "Dialectical hermeneutics: A theoretical framework for the implementation of information systems", Information Systems Journal, 5, 1, 51-70, 1994

[63] H. Richardson, and B. Robinson, "The mysterious case of the missing paradigm: A review of critical information systems research 1991-2001", Information Systems Journal, vol. 7, no. 3, 251-270, 2007.

[64] T. Sutherland, "Social media and the Black travel community: From autonomous space to liberated space", HICSS-52 Proceedings, 2019.

[65] O.K. Ngwenyama, and A.S. Lee, "Communication richness in electronic mail: Critical social theory and the contextuality of meaning", MIS Quarterly, vol. 21, no. 2, 145-167, 1997.

[66] M.D. Myers, and H.K. Klein, "A set of principles for conducting critical research in information systems", MIS Quarterly, vol. 35, no. 1, 17-36, 2011.
[67] D. Cecez-Kecmanovic, "Doing critical IS research: The question of methodology", Qualitative Research in IS: Issues and Trends (pp. 141-162), IGI Global, 2001.

[68] S. Sarker et al., "Learning from first-generation qualitative approaches in the IS discipline: An evolutionary view and some implications for authors and evaluators", Journal of the AIS, 19, no. 8, 752-774, 2018.

[69] M. Alvesson, and S. Deetz, Doing Critical Management Research, SAGE, London, 2000.

[70] G. Lichfield, "Expecting Tim Cook to be openly gay would be to completely forget gay history", Quartz, 2014

[71] J.B. Stewart, "Among gay C.E.O.s, the pressure to conform", New York Times (Jun 2014).

[72] S. Tobak, "Should gay CEOs come out of the closet?", Entrepreneur (July 2014).

[73] T. Cook, "Tim Cook speaks up" Bloomberg (Oct 2014).

[74] Z. Mejia, "What Tim Cook says coming out cost himand why he still has 'no regrets"', CNBC (Jun 2018).

[75] "Talk:Tim Cook", Wikipedia, 2018.

[76] “Talk:Tim Cook/Archive 1”, Wikipedia, 2018.

[77] "Wikipedia:Biographies of living persons/Noticeboard/Archive132", Wikipedia, 2018.

[78] M. Helmsing, "Becoming-American: Experiencing the nation through LGBT fabulation in a ninth grade U.S. history class", J Soc Stud Res, v. 40, no. 3, 173-186, 2016.

[79] S.C. Srivastava, T.S.H. Teo, and S. Devaraj, "You can't bribe a computer: Dealing with the societal challenge of corruption through ICT", MIS Quarterly, vol. 40, no. 2, 511-526, 2016.

[80] K.K. Ganju, P.A. Pavlou, and R.D. Banker, "Does information and communication technology lead to the well-being of nations? A country-level empirical investigation", MIS Quarterly, 40, no. 2, 417-430, 2016.

[81] J. D'Arcy et al., "Reflecting on the "dark side" of information technology use", Communications of the AIS, vol. 35, 109-118, 2014.

[82] X. Deng, K.D. Joshi, and R.D. Galliers, "The duality of empowerment and marginalization in microtask crowdsourcing: Giving voice to the less powerful through value sensitive design", MIS Quarterly, vol. 40, no. 2, 279-302, 2016.

[83] P. Shachaf, and N. Hara, "Beyond vandalism: Wikipedia trolls", Journal of Info. Sci., vol. 36, no. 3, 357-370, 2010.

[84] S. Das, A. Lavoie, A., and M. Magdon-Ismail, "Manipulation among the arbiters of collective intelligence: How Wikipedia administrators mold public opinion”, ACM Trans. Web, vol. 10, no. 4, 2016.

[85] J. Habermas, "Justice and solidarity: On the discussion concerning Stage 6", The Moral Domain (pp. 224-251), MIT Press, Cambridge, 1990.

[86] D.S. Demetis, and A.S. Lee, "When humans using the IT artifact becomes IT using the human artifact", Journal of the AIS, vol. 19, no. 10, 929-952, 2018.

[87] J. Fedorowicz et al., "Politics and AIS: Where do we draw the line?", Communications of the AIS, 44, 247-261, 2019

[88] H.K. Klein, and M.Q. Huynh, "The critical social theory of Jürgen Habermas and its implications for IS research", Social Theory and Philosophy for Information Systems (pp. 157-237). Wiley, New York, 2004.

[89] G.C. Kane, and S. Ransbotham, "Content and collaboration: An affiliation network approach to 
information quality in online peer production communities", Info Systems Res, 27, 2, 424-439, 2016.

[90] A. Majchrzak, M.L. Markus, and J.D. Wareham, "Designing for digital transformation: Lessons for information systems research from the study of ICT and societal challenges", MIS Quarterly, 40, 2, 267-277, 2016

[91] S. Bhatt, and A. Kamal, "Systems and methods for managing digital identities associated with mobile devices" (U.S. Patent Appl. No. 16/134,348), 2018.
[92] Y.K. Golan, Site of Amnesia: The Lost Historical Consciousness of Mizrahi Jewry, Brill, Leiden, 2019.

[93] V. Earnshaw, "Don't let fear of COVID-19 turn into stigma", Harvard Business Review (Apr 2020).

[94] H. Chughtai et al., "Demarginalizing interdisciplinarity in IS research: Interdisciplinary research in marginalization", Communications of the AIS, vol. 46, 296-315, 2020. 